\title{
APRENDRE ANGLÈS PER A PARLAR AMB EL MÓN: REFLEXIONS AL VOLTANT DE L'ENSENYAMENT DE L'ANGLÈS COM A LLENGUA FRANCA GLOBAL*
}

\section{LEARNING ENGLISH TO SPEAK TO THE WORLD: REFLECTIONS AROUND THE TEACHING OF ENGLISH AS A GLOBAL LINGUA FRANCA}

\author{
ENRIC LLURDA \\ Universitat de Lleida \\ ellurda@dal.udl.cat
}

Resum: Aquest article explora les implicacions de la dimensió global de l'anglès com a llengua franca mundial a l'hora d'ensenyar aquesta llengua en el nostre entorn educatiu. S'hi argumenta la necessitat de transcendir el paradigma del parlant nadiu com a model d'aprenentatge i ensenyament per a caminar cap a un model basat en l'usuari competent de la llengua, i s'aprofundeix en la figura del professor ideal des d'aquest punt de vista, així com els reptes que comporta a l'hora d'avaluar la competència lingüística i d'introduir-hi també la competència intercultural.

Paraules clau: Anglès llengua franca, competència intercultural, usuari competent, EFL, ELF.

Abstract: This paper explores the implications of the global dimension of English as a world lingua franca in teaching the language in our educational environment. It is argued that there is a need to transcend the paradigm that looks at the native speaker as the learning and teaching model in order to move towards a model based on the competent language user. The paper also deals with the figure of the ideal teacher from this perspective, as well as the challenges in assessing language competence and in introducing intercultural competence in language teaching.

Key words: English as a lingua franca, intercultural competence, competent user, EFL, ELF.

$\left(^{*}\right)$ Aquest article ha estat possible gràcies al finançament rebut per part del Ministerio de Economía y Competitividad (projecte FFI20I5-67769-P) i de l'Agència de Gestió d'Ajuts Universitaris i de Recerca (projecte 20I7-SGR-I522). 
ENRIC LLURDA

Aprendre anglès per a parlar amb el món: reflexions al voltant de l'ensenyament de l'anglès com a llengua franca global

\section{LA DIMENSIÓ GLOBAL DE L'ANGLÈS}

L'anglès és sens dubte la llengua més popularment estudiada com a llengua estrangera a nivell global i també en el nostre entorn. Si fa unes quantes dècades es podia parlar de certa competència entre l'anglès $i$ el francès a l'hora de determinar l'oferta docent a les escoles i els instituts del nostre país, el debat va quedar superat per l'acceptació per part de gairebé tothom de la imperiosa necessitat d'aprendre anglès i dels avantatges laborals i professionals que un bon coneixement d'aquesta llengua pot reportar als joves.

Quan mirem les causes que han portat fins aquest domini tan clar de l'anglès, és obvi que la principal és la constatació del poder econòmic, polític, militar i cultural dels Estats Units. Aquest poder, afegit a la història prèvia de colonització de bona part del món per part de l'imperi britànic, fa que l'anglès sigui no només una de les llengües més parlades al món com a primera llengua (tot i que en aquesta categoria es veu clarament superada pel xinès, i d'una manera més ajustada per l'espanyol) sinó que és de llarg la llengua més parlada si es comptabilitzen tots els seus parlants, tant els que la parlen com a llengua materna com aquells que l'han afegit al seu repertori lingüístic com a llegua addicional. En aquesta classificació, els parlants d'anglès s'enfilen gairebé als dos mil milions, dels quals una gran majoria són parlants no nadius que viuen en països que corresponen al que Kachru (1986) va anomenar el Cercle Exterior i el Cercle Expansiu (Outer Circle i Expanding Circle, en la terminologia original), que inclouen els països on l'anglès va ser incorporat com a llengua oficial pel fet d'haver format part de l'imperi britànic (Cercle Exterior) i tota la resta de països del món on l'anglès està formant part cada cop més de la vida quotidiana i gran part de la població l'ha après o l'està aprenent (Cercle Expansiu). Si comparem el nombre de parlants nadius amb els no nadius de les llengües més parlades del món veurem que en tots els casos, excepte l'anglès, el nombre de parlants nadius supera clarament el de no nadius, cosa absolutament lògica i esperable. Aquesta proporció, però, no s'aplica al cas de l'anglès, fet que d'alguna manera defineix i explica la seua presència global, aquest estatus únic que el converteix en la més internacional de les llengües del món, o en altres paraules, la llengua franca global. No cal dir que l'adveniment del procés d'interconnexió mundial que avui coneixem com a globalització, i que es caracteritza per una ràpida reducció de l'espai i el temps i una certa relaxació de les fronteres, ha contribuït a la necessitat d'una llengua que faciliti aquesta interconnexió i com a conseqüència ha catapultat encara més l'expansió de l'anglès com a eina útil i necessària per a establir intercanvis lingüístics i comercials entre persones i comunitats d'arreu del món. 
ENRIC LLURDA

Aprendre anglès per a parlar amb el món: reflexions al voltant de l'ensenyament de l'anglès com a llengua franca global

L'anglès és, per tant, una llengua de comunicació a nivell global i aquest fet en determina la naturalesa, de forma que, tal com argumentaré al llarg d'aquest article, no es pot menystenir aquesta especificitat a l'hora d'ensenyar-la i d'aprendre-la, sinó que - ben al contrari- cal incorporar a la pràctica pedagògica aquest estatus de llengua franca global que va molt més enllà de l'àmbit geogràfic restringit de les Illes Britàniques o dels països que Kachru (1986) va anomenar Cercle Interior (Inner Circle), és a dir els que tenen l'anglès com a llengua oficial única o dominant i en els quals la gran majoria d'habitants són parlants nadius d'anglès: el Regne Unit, Irlanda, els Estats Units, Canadà, Austràlia i Nova Zelanda. En paraules de van Essen (2002), l'anglès ha deixat de ser exclusivament anglès, i tal com argumentava Widdowson (I994), l'anglès ja no és propietat exclusiva dels seus parlants nadius, sinó que totes les persones que el parlen arreu del món poden considerar-se'n legítims propietaris amb dret a usar-lo i adaptar la llengua a les seues necessitats específiques.

\section{OBJECTIUS DE L'ENSENYAMENT DE L'ANGLÈS}

Cook (2007) parla de dos tipus d'objectius en l'aprenentatge d'una llengua estrangera: externs i interns. Els externs es relacionen amb l'ús de la llengua fora de la classe: viatjar, llegir premsa i llibres, etc. Per la seua banda, els interns fan referència al desenvolupament mental dels estudiants com a individus: pensar diferent, veure el món d'una nova manera, esdevenir millors ciutadans amb una consciència més gran de l'alteritat, entre altres. Cook argumenta que la major part de propostes metodològiques per a l'ensenyament de llengües durant el segle xx es van centrar en els objectius externs, amb la particularitat que es donava per fet que l'objectiu era comunicar-se amb parlants nadius i per tant calia aproximar la parla de l'aprenent tant com fos possible a la parla dels nadius. Aquesta tendència té un problema de base: ignorar tot el vessant intern en la relació dels objectius i els beneficis d'incorporar una nova llengua al repertori lingüístic propi. Pensar en l'aprenentatge d'una llengua estrangera només com una forma utilitària d'accedir a noves situacions comunicatives és ignorar els múltiples beneficis, tant intel-lectuals com de sensibilitat sociocultural i fins i tot afectius, que es poden obtenir amb l'aprenentatge d'una nova llengua. Però, a més a més, Cook (2007) esmenta un altre problema pel que fa a l'ensenyament de l'anglès en particular. Aquest no és altre que la restricció a priori de les opcions comunicatives externes a només un grup minoritari (els parlants nadius) del total de parlants d'anglès que habiten al món, i la identificació del parlant nadiu com a objectiu de l'aprenentatge d'una llengua estrangera, un objectiu sense cap fonament ni raó de ser, 
ENRIC LLURDA

Aprendre anglès per a parlar amb el món: reflexions al voltant de l'ensenyament de l'anglès com a llengua franca global

donat que l'aspiració lògica de qualsevol aprenent d'anglès com a llengua estrangera és la d'arribar a ser un usuari competent d'aquesta llengua, però mai un parlant nadiu. L'aspiració d'esdevenir un parlant nadiu serial'equivalent a voler suprimir tot el bagatge previ de coneixement lingüístic. Un aprenent d'una llengua estrangera esdevindrà per força un parlant multilingüe amb un repertori lingüístic que inclourà la nova llengua $\mathrm{i}$ totes les llengües que anteriorment ja configuraven el seu repertori. En reflexionar sobre els objectius legítims, realistes i desitjables d'aprenentatge d'una segona llengua o llengua estrangera, Cook (2005) introdueix el concepte d'usuari L2 (L2 user) substituint el del parlant nadiu, que no és realista, i per tant tampoc legítim ni desitjable.

Queda clar amb aquests arguments que l'objectiu d'un aprenent d'anglès no és parlar només amb nadius ni parlar tal com ho fan els nadius, llevat d'aquells casos en els quals el motiu principal de l'aprenentatge de la llengua sigui arribar a formar part de la comunitat lingüística de parlants nadius d'anglès d'un indret concret. Així, per exemple, pot haver-hi persones que per motius personals i afectius decideixin iniciar una nova vida en un entorn social i familiar on s'utilitza l'anglès com a llengua pròpia de la comunitat, i aquest ús de l'anglès té unes característiques definitòries exclusives d'aquella comunitat, tant des del punt de vista purament lingüístic com sociolingüístic i pragmàtic. En aquest context, és lògic pensar que aquesta persona voldrà aprendre o elevar el seu nivell de coneixement de la llengua a partir de la seua necessitat d'adaptar-se al nou entorn sociolingüístic, i en definitiva utilitzarà l'anglès per a comunicar-se amb els membres d'una comunitat específica. Així, doncs, intentarà que la seua parla s'assembli tant com sigui possible a la parla de les persones que formen part de la comunitat a la qual voldria pertànyer.

Deia anteriorment que els mètodes d'ensenyament dominants durant el segle $\mathrm{xx}$ han afavorit objectius externs $\mathrm{i}$ han posat el parlant nadiu com a element central en l'aprenentatge. Aquesta manera d'entendre l'ensenyament de l'anglès, Seidlhofer (200I) la identifica amb el concepte tradicional d'anglès llengua estrangera o $E F L$ (English as a Foreign Language), i hi contraposa una nova manera que seria la que té en compte l'anglès com a llengua franca o ELF (English as a Lingua Franca).

Una forma efectiva d'expressar conceptes és mitjançant l'ús de metàfores que ens ajuden a visualitzar el sentit de cada concepte i les diferències entre aquests. Així, podem copsar la diferència essencial entre aquestes dues formes d'entendre l'ensenyament de l'anglès (EFL i ELF) amb una metàfora que al meu parer en captura perfectament el sentit i els matisos. Aquesta metàfora deriva de l'associació de l'anglès a un instrument que permet que persones situades en entorns llunyans puguin establir contacte entre elles. Si aquesta llunyania la visualitzem com una superfície aquàtica, com pot ser un riu o un estret, ens apareix de forma força òbvia la metàfora de l'anglès com un pont 
ENRIC LLURDA

Aprendre anglès per a parlar amb el món: reflexions al voltant de l'ensenyament de l'anglès com a

que uneix terres, cultures i gent. De fet, la metàfora del pont ha estat àmpliament utilitzada per a referir-se a les llengües, possiblement la més utilitzada juntament amb la metàfora de la finestra (em refereixo a allò tan repetit que una llengua és una finestra oberta al món). En definitiva, doncs, podríem dir que la metàfora del pont és una que tradicionalment ha funcionat per a descriure la funció d'una llengua estrangera. Ara bé, el meu argument aquí és que aquesta metàfora funciona només si es té una concepció tradicional de l'aprenentatge de l'anglès, equivalent a la idea d'EFL expressada per Seidlhofer (200I). En altres paraules, podríem dir que l'anglès és com un pont que ens permet anar fins a la costa anglesa, o a l'americana, que per al cas seria el mateix. Aprendre anglès, sota aquesta perspectiva, ens permet parlar amb persones que tinguin l'anglès com a llengua pròpia, i l'objectiu d'aprendre la llengua és poder-nos comunicar amb alguna de les comunitats de parlants nadius. Cal remarcar que el pont és una estructura molt vàlida i útil, però que tanmateix té una limitació important: només ens permet anar a un punt concret a l'altra banda de l'aigua, és a dir és una estructura limitadora pel que fa a la destinació. Si bé és cert que, un cop arribats a l'altra banda, ja serà més facil resseguir la costa i anar trobant noves persones i noves comunitats, el pont en principi només ens porta a un punt geogràfic concret i ens facilita la comunicació amb un grup limitat de persones.

Si el pont és una metàfora que captura la idea tradicional associada a l'aprenentatge de l'anglès com a llengua estrangera, quina podria ser, doncs, una metàfora vàlida per a expressar la idea de l'aprenentatge de l'anglès com a llengua franca? Quina imatge ens permet transcendir la rigidesa d'haver de passar sempre pel mateix punt de destí en el procés d'aprenentatge? Com podem expressar que l'objectiu de l'aprenentatge no és comunicar-se exclusivament (ni tan sols primordialment) amb la comunitat de parlants nadius, sinó desenvolupar un grau de comunicabilitat suficient per a poder entrar en contacte amb parlants d'arreu del món? Per a mi, la metàfora que pot mostrar de forma clara la flexibilitat, obertura, adaptabilitat i globalitat de l'anglès com a llengua franca és la d'un vaixell. Un vaixell que ens permetrà anar a l'altra riba o a l'altra banda de l'estret, però que també ens permetrà navegar pels set mars i arribar al port més llunyà. Un vaixell ens dona la capacitat d'explorar noves zones i de variar la ruta si és necessari. Els vaixells tenen característiques diferents. Alguns són transatlàntics i altres són petits vaixells de pesca. Altres són molt especialitzats, naveguen per tot el món transportant un tipus de producte molt particular (petroli, per exemple) mentre que altres estan més fets per a lluir que per a treballar. Són diversos, i a vegades fins i tot poden patir accidents i enfonsar-se, igual que les converses en anglès entre persones d'indrets diferents a vegades no arriben a bon port i es trenca el flux comunicatiu per falta d'entesa mútua. Però, en general, acostumen a ser resistents i s'adapten a les 
ENRIC LLURDA

Aprendre anglès per a parlar amb el món: reflexions al voltant de l'ensenyament de l'anglès com a llengua franca global

condicions i inclemències del temps, i en definitiva compleixen la funció de permetre la comunicació amb qualsevol persona o comunitat del món.

Queda clar, doncs, que l'ensenyament de l'anglès tal com s'entén al segle XxI, dins del paradigma de l'anglès com a llengua franca, seria més similar a la idea del propòsit i funció d'un vaixell que no pas a la d'un pont. La diferència es troba en la flexibilitat, mobilitat i adaptabilitat per una banda, vers la rigidesa i l'immobilisme per l'altra. Al segle xxi, en un món plenament globalitzat, l'anglès és un mitjà que ens ha de permetre comunicar-nos amb qualsevol persona o grup de qualsevol part del planeta, de forma que obri nous camins d'intercanvi i de contacte fluid entre membres de comunitats diferents.

Fora de la circumstància, esmentada més amunt, d'aquelles persones que aprenen anglès per integrar-se plenament en una comunitat concreta ben delimitada geogràficament, lingüística i cultural, de parlants nadius — una circumstància absolutament minoritària en el conjunt d'aprenents d'anglès al nostre país, i m'atreviria a dir que també a la resta del món-, l'objectiu central que caracteritza l'aprenentatge de la llengua és arribar a una eficiència màxima en contextos diversos i amb gent diversa provinents de llocs i cultures diferents. En resum, podríem dir que allò que realment es persegueix i és desitjable en l'aprenentatge d'anglès com a llengua estrangera es podria resumir en dos conceptes essencials: la intel-ligibilitat mútua i la consciència intercultural.

En relació a la intel-ligibilitat de la parla, hi ha diferents aspectes lingüístics que hi influeixen. A partir d'alguns dels estudis que s'hi han referit en el cas de l'anglès (Crowther et alii 20I4; Derwing \& Munro 20I5), podem concloure que l'ús de lèxic infreqüent i d'errors gramaticals perjudica la comprensió de la parla. D'altra part, parlar amb fluïdesa, usar seqüències idiomàtiques familiars i referir-se a temes familiars, així com estar avesat a l'accent concret de la persona que parla, reforça el grau de comprensió del que s'està dient.

Partint del model dels tres cercles concèntrics (interior, exterior i expansiu) de Kachru (1986), Modiano (1999) en va fer una reformulació en la qual proposava que la intel-ligibilitat en entorns comunicatius internacionals se situés en el cercle central. Així, en lloc de visualitzar com a element central els parlants de països com el Regne Unit, els Estats Units, etc., el que fa Modiano és posar al centre tots aquells parlants — siguin d'on siguin - que poden comunicar-se de forma efectiva i eficient, o sigui de forma plenament intel.ligible davant de qualsevol altre parlant internacional. Per contra, el segon cercle està format per aquells parlants competents en anglès (tant nadius com no nadius) que malgrat la seua competència no han desenvolupat prou habilitats comunicatives en entorns internacionals $\mathrm{i}$, per tant, mostren greus problemes 
ENRIC LLURDA

Aprendre anglès per a parlar amb el món: reflexions al voltant de l'ensenyament de l'anglès com a

a l'hora de comprendre i/o de ser compresos per altres parlants competents provinents d'altres indrets. En el nivell exterior, Modiano hi situa totes aquelles persones que estan en fase d'aprenentatge i que per tant encara no són usuaris competents de la llengua. Els aspectes més notables d'aquest model són, per una banda, el dinamisme que comporta pel fet que els parlants poden anar evolucionant i canviant de cercle amb una tendència centrípeta d'acostament progressiu cap al centre, i per l'altra, el fet que els parlants nadius i no nadius comparteixen els dos cercles centrals, de forma que la pertinença a un o a l'altre no depèn de la llengua materna del parlant sinó de la capacitat comunicativa amb persones provinents d'altres punts del món, és a dir, de la capacitat d'ús efectiu de l'anglès com a llengua franca. Hi ha nadius que se'n surten comunicant-se exitosament amb parlants d'orígens diversos, i altres que no. Igual com hi ha parlants no nadius que se'n surten i altres que no.

Fixem-nos que Modiano posa els aprenents de la llengua en el tercer cercle, ja que són les persones que més han de treballar per arribar al cercle central de l'eficàcia comunicativa, però que, així i tot, hi poden arribar un cop adquireixin la competència necessària. Aquesta idea lliga molt bé amb el qüestionament de la distinció entre parlants nadius i no nadius que ens ha aportat la literatura dels darrers vint anys, així com la distinció feta per Cook (2005) entre aprenents i usuaris de L2. El qüestionament de la distinció entre nadius i no nadius es va fer més intens durant la darrera dècada del segle Xx. Diversos autors (Rampton 1990; Davies 199I, 2003; Cook 1999; Liu 1999; Brutt-Griffler \& Samimy 200I) han qüestionat les bases teòriques d'aquesta distinció negant que hi hagi cap argument sòlid per a mantenir una separació que diferencia els parlants d'una llengua en parlants que podríem anomenar de primera (els nadius) i parlants de segona (els no nadius). Davies (I99I, 2003) és qui dedica més esforços a caracteritzar el parlant nadiu i finalment conclou que no hi ha cap propietat lingüística que distingeixi els nadius dels no nadius, i per tant el fet que un individu es pengi l'etiqueta de parlant nadiu o no nadiu respon a una tria que fa l'individu mateix per ser reconegut com a tal i a l'acceptació per part de la resta de parlants. És a dir, es basa en la lliure associació a un constructe i la percepció que en tenen els altres, però no es pot definir a partir de cap element competencial ni de capacitat comunicativa. Això és fonamental perquè ens permet obviar la categoria nadiu / no nadiu a l'hora de valorar les competències lingüístiques d'un parlant, i ens permet centrar-nos en allò que aquesta persona pot fer amb la llengua. En altres paraules, ens permet mesurar fins a quin punt aquest parlant és un usuari competent o no de la llengua. A partir d'aquí pren validesa la recerca al voltant del concepte de nous parlants (new speakers) tal con la formulen O'Rourke \& Pujolar (2013) en el context de llengües minoritàries/ minoritzades, donat que aquests nous parlants són percebuts com l'única esperança 
ENRIC LLURDA

Aprendre anglès per a parlar amb el món: reflexions al voltant de l'ensenyament de l'anglès com a llengua franca global

de salvació de la llengua en perill d'extinció. També resulta convenient d'enfocar-nos en la distinció formulada per Cook (2005) entre usuaris de L2 i aprenents de L2. Per a Cook, els usuaris són aquelles persones que han mostrat a bastament que poden comunicar-se en la L2, poden comprendre i ser compresos, poden interaccionar i arribar a expressar idees, emocions i a solucionar conflictes. En canvi, els aprenents encara no han desenvolupat una capacitat plena per a dur a terme aquestes funcions. En certa manera, podríem dir que un aprenent es troba encara en una fase infantil en la qual necessita l'adult per a guiar-lo i per a determinar què pot fer i què no pot fer, mentre que un usuari consolidat ja ha assolit un grau de maduresa prou alt com per a poder prendre les seues pròpies decisions i interactuar en un plànol d'igualtat amb la resta d'usuaris.

Aquesta caracterització xoca amb la tendència encara força generalitzada de reduir tots els parlants d'una segona llengua a la categoria d'aprenents perennes. Quan algú és identificat com a «aprenent» d'una llengua pel sol fet de no tenir-la com a llengua materna, se li està negant la capacitat d'interactuar sense l'aval i la validació dels parlants nadius. En altres paraules, si bé és cert que sempre es pot seguir aprenent aspectes d'una llengua (fins i tot en la pròpia llengua materna), hi ha un moment en l'evolució lingüística d'una persona que ha assolit un cert nivell de perícia que allò que el defineix no és allò que li falta i que encara ha d'aprendre, sinó allò que ja té: tot el que pot fer amb la llengua. I per tant, és il-lògic continuar referint-se a aquestes persones com a aprenents d'una llengua de la qual són uns usuaris consolidats. En aquest sentit, és interessant fixar-nos en allò que diu Piller (2002), tot rebutjant la classificació binària entre parlants nadius i no nadius. Piller descriu la identitat del parlant nadiu de forma dinàmica, de manera que els individus no s'inclouen totalment en una sola categoria i poden, en canvi, moure's de l'una a l'altra, segons el tipus d'actuació comunicativa en la qual s'implica el parlant, la incorporació d'elements de la parla locals coincidents amb els estereotips de l'audiència, el mitjà (oral, escrit, electrònic) utilitzat per a les interaccions comunicatives, i els interlocutors. El fet de ser considerat un parlant nadiu o no depèn d'elements contextuals més que no pas d'un tret identitari. Llurda (2016) incorpora, a més a més, la idea que l'ús persistent de la categorització dels parlants de forma binària i la seua classificació en nadius i no nadius contribueix al desempoderament dels que s'inclouen en la darrera categoria i la seua minusvaloració en tots els àmbits professionals, especialment en el de l'ensenyament de llengües.

La constatació que l'anglès és una llengua d'ús global que s'expandeix molt més enllà de les fronteres estrictes dels països del Cercle Interior (Kachru 1986) on la majoria de ciutadans tenen l'anglès com a llengua materna ens porta a preguntar-nos 
ENRIC LLURDA

Aprendre anglès per a parlar amb el món: reflexions al voltant de l'ensenyament de l'anglès com a llengua franca global

com podem promoure entre els aprenents una visió més oberta basada en el seu ús com a llengua franca (ELF). En altres paraules, i tornant a la metàfora del pont i del vaixell, la pregunta pertinent seria com treballar per a construir vaixells (ELF) en lloc de ponts (EFL) a la classe d'anglès. I malgrat que no disposem d'una proposta concloent sobre com enfocar l'ensenyament de l'anglès amb una visió ELF, sí que podem apuntar cap on haurien d'anar els esforços. Així, podem parlar d'una pedagogia amb visió ELF quan:

(a) Minimitzem el treball al voltant de formes idiomàtiques locals parlades per grups específics de parlants nadius i ens centrem en aquells aspectes de la llengua que són compartits internacionalment per la majoria dels parlants, tant nadius com no nadius.

(b) Potenciem les estratègies de comunicació i adaptació per damunt de la correcció en els aspectes formals del llenguatge (gramàtica, pronunciació, lèxic, etc.).

(c) Ens centrem en la diversitat lingüística i cultural, especialment a l'hora de mostrar exemples de parla i escriptura per al treball de la comprensió oral i escrita.

Cal dir que, en la mateixa línia de les idees presentades en aquest article, darrerament s'han publicat alguns llibres que desenvolupen propostes detallades pel que fa a la incorporació d'una visió inspirada per la dimensió global de l'anglès com a llengua franca en l'ensenyament d'aquesta llengua (Alsagoff et alii 20I2; Bayyurt \& Akcan 20I5; Marlina \& Giri 20I4; Matsuda 20I2, 20I7; Sifakis \& Tsantila 20I9).

\section{COM HA DE SER EL PROFESSOR D’ANGLÈS IDEAL?}

Davant d'una situació d'ús pràcticament global de l'anglès com la descrita anteriorment, la figura del professorat no pot ser la mateixa de quan es concebia l'anglès com una llengua propietat dels seus parlants nadius, i particularment pel que fa a les classes d'anglès al continent europeu, dels parlants de l'estàndard britànic. En aquella visió de la classe d'anglès com un pont que ens permetria arribar fins al cor de la city londinenca, es valorava l'ús de formes col-loquials pròpies d'aquella comunitat lingüística i la pronunciació tan semblant com fos possible a la d'un grup específic (molt elitista) de parlants nadius britànics. Si l'objectiu era acostar els aprenents a aquell entorn geogràfic i cultural, calia que el professor fos un exponent tan proper com fos possible de la parla d'aquell entorn, i això invariablement portava a pensar que el professor ideal era un parlant nadiu. Tot aquell que no fos un nadiu era en certa manera un impostor

Caplletra 68 (Primavera, 2020), p. 199-217 
ENRIC LLURDA

Aprendre anglès per a parlar amb el món: reflexions al voltant de l'ensenyament de l'anglès com a llengua franca global

o un substitut defectuós del model ideal. Ara bé, un cop l'objectiu s'ha reformulat i ja no és construir un pont que porti els alumnes a la city sinó una embarcació que els permeti navegar per tots els confins del planeta, les condicions ideals del professorat han de ser forçosament diferents. Ara, igual que abans, cal un individu que sigui capaç de parlar la llengua amb fluïdesa i sentir-se còmode mentre ho fa, però no cal ni és pas desitjable ser un parlant nadiu o maldar per assemblar-s'hi fins al punt d'intentar esdevenir una mena de clon de nadiu (un objectiu que a vegades es percep en alguns professors d'anglès que han interioritzat la necessitat de mostrar el camí cap al reduït grup de parlants nadius d'estàndard britànic). Ser nadiu no garanteix haver arribat al nivell màxim de domini d'una llengua. De fet, tal com afirma Davies (2003), molts parlants nadius no passarien una prova de $\mathrm{C}_{2}$ de la seua llengua materna, mentre que molts parlants no nadius, en canvi, han assolit sobradament aquest nivell. D'altra banda, el que necessita l'aprenent és algú que el guiï i l'ajudi a progressar en l'ús de l'anglès en qualsevol entorn i circumstància. I, sens dubte, qui millor pot ajudar un aprenent a esdevenir un usuari d'anglès com a L2 competent i multilingüe és un professor que també sigui competent en anglès $i$ alhora multilingüe. En aquest sentit, hi ha hagut força recerca en els darrers anys que ha posat de manifest la contribució altament positiva del professorat no nadiu (Braine 20ı0; Llurda 2005; Moussu \& Llurda 2008). La coincidència en el temps del despertar en la recerca tant de l'anglès com a llengua franca com de la figura del professorat no nadiu no és pas casual, ja que l'ús de l'anglès com a llengua franca es caracteritza pel fet que una gran majoria dels seus usuaris són parlants no nadius, i que en un entorn de llengua franca la comunitat amb la qual es pretén arribar a comunicar-se és global i per tant no lligada a cap població nadiua en concret (Llurda 20r8). No cal pas que sigui nadiu, i per descomptat no és pas recomanable que sigui un parlant monolingüe d'anglès. Aquest no és el cas de la majoria de professors nadius que ensenyen anglès al nostre país però sí que encara avui molts centres privats d'ensenyament de llengües prefereixen un parlant monolingüe anglès a un parlant multilingüe que coneix bé com a mínim l'anglès, el català i el castellà, i valoren especialment el ganxo comercial que suposa per al seu negoci tenir un professor nadiu acabat d'arribar (Calvet 20I8). Finalment, cal remarcar una cosa que no per òbvia deixa de ser important: les habilitats docents i pedagògiques són individuals i absolutament independents de la condició de parlant nadiu o no nadiu del professor. Un bon professor es defineix per allò que fa a la classe i no per la seua nacionalitat o pel lloc on ha viscut durant la seua infancia (Llurda 2009). 
ENRIC LLURDA

Aprendre anglès per a parlar amb el món: reflexions al voltant de l'ensenyament de l'anglès com a

\section{ENSENYAR I AVALUAR L'ANGLÈS COM A LLENGUA FRANCA}

Per damunt de tot, quan parlem d'un enfocament pedagògic basat en l'anglès com a llengua franca estem incidint en la importància cabdal dels aspectes comunicatius per damunt dels apriorismes formals. Fins i tot en els anys en els quals l'enfocament comunicatiu estava en ple apogeu, molts dels seus defensors s'oblidaven d'incloure-hi multitud de situacions comunicatives reals entre parlants no nadius per a centrar-se exclusivament en una idealitzada forma de comunicació entre parlants nadius. Així, doncs, un enfocament que tingui en compte l'anglès com a llengua franca haurà de prioritzar per damunt de tot alguns aspectes rellevants per a la comunicació.

En primer lloc, cal potenciar la intel.ligibilitat, les estratègies comunicatives i la capacitat de superar problemes durant la conversa. En definitiva, cal donar eines per a optimitzar el resultat de la interacció i per superar els potencials daltabaixos comunicatius que puguin aparèixer, encara que això suposi sacrificar temps i esforços dedicats a l'estudi de les estructures formals, moltes de les quals tenen un impacte insignificant en el flux comunicatiu de la gran majoria de les interaccions en anglès a escala global. Cal fer una tria d'aquells elements formals que són bàsics per a la intercomprensió dels parlants i prioritzar-los per damunt d'aquells que són merament accessoris.

Pel que fa a la pronunciació, l'aspecte menys rellevant és imitar un accent nadiu en concret, i per contra cal centrar-se en aspectes que són determinants per a la intelligibilitat d'allò que s'està dient. Encara que calen més estudis per a determinar quins són aquests aspectes clau, Jenkins (2000) parla d'elements fonètics essencials per a la intel.ligibilitat, que anomena lingua franca core, en contraposició a uns altres d'irrellevants, com per exemple la pronunciació de les vocals, ja siguin tòniques o àtones. Els elements que ella considera rellevants són l'articulació acurada de les consonants (amb l'excepció dels dos fonemes interdentals, sord i sonor), l'aspiració dels sons oclusius sords en posició inicial, la pronunciació de tots els sons en els grups consonàntics, el contrast entre vocals llargues i curtes, i finalment en el plànol suprasegmental, l'ús adequat de l'accentuació tònica amb finalitat contrastiva.

Una altra recomanació a tenir en compte en una pedagogia centrada en l'anglès com a llengua franca és la tolerància a la barreja lliure d'elements lingüístics propis de diverses varietats de l'anglès. Quan l'objectiu últim no és la imitació fidedigna d'una varietat de parla concreta sinó la intel-ligibilitat global, té molt poca rellevància si una opció lingüística concreta correspon a una varietat o a una altra. Per exemple, la pronunciació del fonema $/ \mathrm{r} / \mathrm{a}$ final de síl-laba és característic de la varietat estàndard dels Estats Units, mentre que no es troba en la varietat britànica. Alhora, l'estàndard americà té tendència a produir un so aproximant semblant a la $r$ catalana (anomenat 
ENRIC LLURDA

Aprendre anglès per a parlar amb el món: reflexions al voltant de l'ensenyament de l'anglès com a llengua franca global

alveolar flap en anglès) en paraules on trobem per escrit dues $t$ intervocàliques (per exemple: better o cotton). L’estàndard britànic, per contra, opta per pronunciar $/ \mathrm{t} / \mathrm{en}$ aquests mots, encara que en parles col-loquials britàniques és força freqüent trobar una oclusiva gutural (glottal stop) en lloc de l'oclusiva alveolar de l'estàndard. Entre totes aquestes opcions, sembla força raonable adherir-se a la proposta de Jenkins (2000) de potenciar en els parlants d'anglès en entorns internacionals la pronunciació del fonema /r/ final i la realització del so oclusiu alveolar /t/ (o fins i tot la seua versió dental si hi ha dificultat a portar la llengua en contacte amb els alvèols). Per tant, només amb aquests dos exemples trobem que el criteri de fomentar la intel.ligibilitat entre parlants diversos ens porta a preferir en un cas una forma associada amb l'estàndard americà $\mathrm{i}$ en l'altre una forma usada en l'estàndard britànic. Això entra de ple en contradicció $\mathrm{amb}$ un principi freqüentment repetit per alguns professors d'anglès al nostre país, els quals reclamen els aprenents que se cenyeixin exclusivament a una varietat nadiua, preferentment la britànica o l'americana, sense barrejar elements de l'una a l'altra. Des d'una perspectiva internacional, aquest principi esdevé absurd i irrellevant davant del criteri de la intel.ligibilitat. Fent un símil amb la llengua catalana i el seu procés normatiu liderat per Fabra, el principi de la «consistència varietal» vindria a dir que el llenguatge escrit hauria de seguir el patró de pronunciació d'una sola varietat. Precisament, una de les grans virtuts de la normativa de Fabra va ser la inclusió en l'ortografia de normes que representen la pronunciació de varietats diferents en lloc de basar-se exclusivament en una sola varietat dialectal. Podem argumentar que la filosofia que inspira ELF també busca potenciar l'ús de solucions provinents de diferents varietats de l'anglès, i no necessàriament han de ser varietats parlades per parlants nadius.

La idealització del mètode comunicatiu com a mètode de referència en l'ensenyament de l'anglès ha portat alguns professors a voler introduir el màxim d'aspectes propis de la comunicació «natural» dels parlants nadius. Així, hi ha professors que consideren important dedicar temps a treballar la parla col-loquial d'algun grup humà (en el nostre entorn acostuma a ser la de la població urbana britànica) i això porta a treballar expressions i formes molt localitzades en àrees geogràfiques concretes, pertanyents al registre col-loquial i amb poc abast fora del seu entorn immediat (slang). La perspectiva ELF propugna simplement ignorar i no dedicar cap mena d'atenció a aquestes formes, per tal d'alliberar espai i temps per a treballar elements més susceptibles de ser utilitzats a escala global, així com estratègies comunicatives i de reparació, útils per a mantenir viva la interacció en els moments en què la comunicació no flueixi prou.

Seidlhofer (2003) argumenta que una visió realista de l'ensenyament de l'anglès ha de tenir en compte que l'objectiu d'un aprenent no és esdevenir un altre parlant 
ENRIC LLURDA

Aprendre anglès per a parlar amb el món: reflexions al voltant de l'ensenyament de l'anglès com a

llengua franca global

nadiu sinó un parlant competent que indefectiblement serà bilingüe, o fins i tot multilingüe. I certament, encarar la llengua de forma realista implica, per una banda, acceptar el multilingüisme com a expressió natural de la comunicació humana i, per l'altra, trencar amb el dogma monolingüe imperant en l'ensenyament de l'anglès.

En aquesta mateixa línia, i seguint la línia d'altres investigadors que aprofundeixen en la importància d'aprofitar els coneixements de la Li que té l'aprenent per a optimitzar el procés d'aprenentatge d'una L2 (Corcoll \& González-Davies 20ı6; González-Davies 20I7), s'està desenvolupant a la Universitat de Lleida el projecte de recerca titulat «Cap a una perspectiva plurilingüe en l'ensenyament de l'anglès com a llengua franca a la universitat (PLURELF)», encaminat a analitzar l'impacte d'una pràctica pedagògica clarament enfocada a desenvolupar la competència plurilingüe dels aprenents des d'una perspectiva coherent amb la formulació de l'anglès com a llengua franca, en un entorn de classe universitària d'anglès empresarial, amb alumnes de primer d'estudis d'Administració i direcció d'empreses. En aquest projecte hem pogut ja obtenir dades que apunten a un benefici en la millora oral dels alumnes, malgrat un cert rebuig inicial a la metodologia i una clara resistència a la novetat que suposa respecte de la forma d'ensenyament tradicional, que no té en compte la competència prèvia de l'aprenent en la seua Li i en altres llengües que pugui conèixer.

\section{LA DIMENSIÓ CULTURAL D’UNA LLENGUA FRANCA}

Una llengua difícilment es pot estudiar sense estudiar la cultura amb la qual s'associa. Aprendre una llengua determinada implica entrar poc o molt en contacte amb la seua cultura. Això és obvi en el cas de llengües molt delimitades en un espai físic concret i que normalment tenen uns trets culturals facilment reconeixibles, però no ho és tant en el cas de llengües molt esteses en diferents països i regions del planeta. El cas de l'anglès és paradigmàtic, tant per la diversitat de països on es parla com a llengua dominant (tan distanciats geogràficament com el Regne Unit, els Estats Units i Austràlia, per esmentar-ne només uns quants) com per la seua presència com a llengua franca arreu del món. Si, tal com afirma Kachru (1986), l'anglès també és una llengua asiàtica, convindrem que no podem cenyir la seua cultura als estereotips associats al Regne Unit i ens haurem de plantejar formes d'incloure tota la diversitat cultural expressada en anglès en el marc de l'ensenyament d'aquesta llengua. La perspectiva d'ensenyar totes les diverses cultures susceptibles de ser expressades en anglès, és a dir, tota la diversitat cultural mundial, és aclaparadora, i sens dubte seria 
ENRIC LLURDA

Aprendre anglès per a parlar amb el món: reflexions al voltant de l'ensenyament de l'anglès com a llengua franca global

una empresa impossible d'assolir. Davant d'això, hi ha la temptació de replegar-se i centrar-se només en aquells aspectes culturals directament identificables amb els dos països paradigmàtics: el Regne Unit i els Estats Units. Crec que no és una bona idea. Al meu parer, la forma més sensata i realista d'encarar els aspectes culturals en una classe d'anglès com a llengua franca és plantejant-se una visió oberta cap a la diversitat cultural global i posant-se com a objectiu el desenvolupament de la competència intercultural. Aquesta competència evita centrar-se en productes culturals concrets per a incidir en les capacitats de l'individu que facilitin el contacte i l'intercanvi d'experiències amb altres individus, siguin d'on siguin.

Sercu et alii (2005) van elaborar la següent llista de principis que caracteritzen una persona amb un alt nivell de competència intercultural:

i. Ganes d'implicar-se amb la cultura estrangera.

ii. Autoconsciència i capacitat de mirar-se un mateix des de fora.

iii. Habilitat de veure el món amb els ulls dels altres.

iv. Habilitat per gestionar la incertesa.

v. Habilitat d'actuar com a mediador cultural.

vi. Habilitat d'avaluar el punt de vista dels altres.

vii. Comprendre que els individus no es poden reduir a les seues identitats col-lectives.

Plantejar-se l'assoliment d'aquestes característiques és un objectiu molt ambiciós i gens facil. Tanmateix, és molt més realista que qualsevol altre objectiu basat en la identificació cultural de l'anglès amb les obres i els costums de l'elit d'un país determinat. Tots aquests objectius permeten anar avançant en una sèrie de qualitats que permetran a l'individu interactuar en entorns i circumstàncies variats. En paraules de Sercu et alii (2005: 2):

l'experiència intercultural requereix la revisió de creences, conceptes i actituds que hom havia donat per sabudes. El procés fa que les persones revisin la seua identitat social, que reconsiderin les idees que tenien sobre els grups externs, i que reconsiderin la seua posició en relació a aquests grups externs ja que ara ells també formen part del grup extern. ${ }^{1}$

Resulta també adequat aquí, citar un fragment de Risager (2007: 205) on l'autora reflexiona sobre la importància de l'autoreflexió com a component essencial del procés d'aprenentatge de llengües:

I. Tant aquesta traducció com les següents de fragments en anglès són meues. 
ENRIC LLURDA

Aprendre anglès per a parlar amb el món: reflexions al voltant de l'ensenyament de l'anglès com a llengua franca global

\begin{abstract}
L’ensenyament de llengües —a més de promoure la competència lingüística/comunicativa - ha d'ajudar els estudiants a expandir el seu coneixement del món [...]

Per coneixement 'del món' vull dir una comprensió del 'tot el món', una comprensió que també és auto-reflexiva: qui soc jo, i on em situo en el context global —econòmicament, políticament, socialment, culturalment i lingüísticament? En quin sentit soc un ciutadà del món, i què és el que això implica?
\end{abstract}

En aquest sentit, Kramsch i Whiteside (2007: 918) reblen el clau argumentant que un aprenent de llengües és algú que «no solament incrementa coneixement lingüístic sinó que també experimenta una nova manera de sentir, de pensar i de comportar-se», i, en definitiva, aquest canvi actua sobre tots els seus rols i posicions socials. Més encara quan aquesta llengua que s'aprèn és la clau per a accedir a tot el món. En altres paraules, és la llengua que obre les portes per a comunicar-se amb ciutadans de qualsevol altre país i permet intercanviar coneixements i experiències molt més enllà de les pròpies vivències anteriors.

Risager (2007) parla de dos paradigmes diferenciats a l'hora d'ensenyar una llengua i la seua cultura: nacional i transnacional. En el nacional, l'objectiu únic és la norma estàndard dels parlants nadius, el professor ideal és un parlant nadiu que utilitza l'estàndard, l'ensenyament es fa exclusivament utilitzant la llengua meta en la seua variant estàndard, els discursos es concentren en les relacions culturals i socials del país o un dels països on es parla la llengua com a llengua nacional, i només la cultura majoritària hi té cabuda, menystenint altres cultures minoritàries que també puguin existir dins d'aquell país, i els subjectes són contextualitzats nacionalment com a pertanyents a un país (per exemple: aquest fenomen és francès o britànic...). Per contra, el paradigma transnacional transcendeix aquesta limitació nacional marcada pel que Billig (I995) va anomenar el «nacionalisme banal», aquell que de tan present com és a tot arreu ja ni tan sols és percebut com a nacionalisme, però que tenyeix bona part de les actuacions i els judicis que es fan dels actes propis i aliens. En definitiva, es tracta, seguint el que proposen Byram i Risager (I999), que els professors incrementin la seua pròpia competència cultural i intercultural, esforçant-se per canviar els seus mètodes a fi de promoure aquestes capacitats en els seus estudiants, $i$ alhora considerar com canviar la seua pròpia identitat professional, deixant de ser un professor de llengua per a esdevenir un professor de competència intercultural. Tal com afirma Menard-Warwick (2008), els professors interculturals tenen molt per oferir, mentre que aquells professors amb poc contacte amb altres cultures necessitaran formar-se intensament per tal de poder incorporar aspectes d'interculturalitat en la seua pràctica docent. El que de debò es necessita, diu Menard-Warwick, és un professorat que

Caplletra 68 (Primavera, 2020), p. 199-217 
ENRIC LLURDA

Aprendre anglès per a parlar amb el món: reflexions al voltant de l'ensenyament de l'anglès com a llengua franca global

hagi viscut experiències de vida que l'hagin dut a assolir un alt grau de competència intercultural.

\section{APUNTS FINALS}

Ja hem vist que el paper de l'anglès com a llengua franca té implicacions en la forma com s'ensenya i ens porta també necessàriament a aprofundir encara més en les propostes que des d'una altra perspectiva han promogut el desenvolupament de la competència intercultural com un factor essencial a la classe de llengües estrangeres. Tanmateix, i deixant ara de banda les qüestions (inter)culturals per tornar a enfocar-nos exclusivament en el llenguatge, una pregunta recurrent que apareix en la discussió sobre la necessitat d'incorporar la visió de llengua franca en l'ensenyament de l'anglès és com podem avaluar l'anglès des d'aquesta perspectiva. $\mathrm{O}$, dit d'una altra manera: podem avaluar una llengua sense basar-nos en un estàndard totalment establert? Cal recordar que la formulació de l'anglès com a llengua franca no es fonamenta en l'establiment d'un nou estàndard que substitueixi els ja existents, sinó en l'aparició de formes comunicatives diverses i variables que, amb l'ajut d'estratègies comunicatives i grans dosis de consciència lingüística, permeten la comunicació entre persones d'orígens diversos.

L'avaluació és l'aspecte més resistent als canvis en la didàctica de llengües i per tant no serà facil que el professorat i els agents implicats en l'avaluació dels nivells assolits pels aprenents d'anglès al nostre país es replantegin els elements en què basen tal avaluació, però és important anar insistint en la idea que molts dels ítems que s'utilitzen avui per a avaluar la llengua no són uns indicadors acurats del nivell de competència comunicativa de l'aprenent en entorns globals on l'anglès s'haurà d'usar amb gent provinent de tot el món. Cal, per tant, un canvi en la cultura de l'avaluació. Hem de passar de buscar errors - entesos com aquelles formes que s'aparten del model idealitzat del parlant nadiu - a valorar tot el que l'aprenent pot fer amb el llenguatge, i a tenir present com articula el seu discurs. És a dir, hem de poder avaluar com de coherent i comprensible per al conjunt de la població potencialment receptora és la persona que produeix un text oral o escrit, i també com de capaç és aquesta persona de modular la seua producció i negociar-ne el sentit i les formes per tal d'arribar a l'objectiu últim de la comunicació satisfactòria amb l'interlocutor. En definitiva, hem de pensar detingudament com podem avaluar de forma justa els parlants d'anglès, sense rigideses formals que ens apartin de l'objectiu comunicatiu que és al darrere de tota producció lingüística, sempre tenint en compte que hi ha contextos més tolerants que 
ENRIC LLURDA

Aprendre anglès per a parlar amb el món: reflexions al voltant de l'ensenyament de l'anglès com a llengua franca global

altres i que el nivell de satisfacció dependrà del nivell de tolerància de l'interlocutor envers les formes lingüístiques que s'aparten de l'estàndard. ${ }^{2}$

ENRIC LLURDA

Universitat de Lleida

ellurda@dal.udl.cat

ORCID 0000-0002-2943-7092

\section{REFERÈNCIES BIBIOGRÀFIQUES}

Alsagoff, L., S. L. McKay, G. Hu \& W. A. Renandya, ed. (20I2) Principles and Practice for Teaching English as an International Language, Nova York, Routledge. Bayyurt, Y. \& S. Akcan, ed. (2015) Current Perspectives on Pedagogy for English as a Lingua Franca, Berlin, de Gruyter.

Billig, M. (I995) Banal Nationalism, Londres, Sage.

Braine, G. (20IO) Non-native Speaker English Teachers. Research, Pedagogy, and Professional Growth, Nova York, Routledge.

BRUtT-GRIfFler, J. \& K. SAMimy (200I) «Transcending the nativeness paradigm», World Englishes, 20 (I), p. 99-I06. DOI: I0.IIII/I467-97IX.00I99

Byram, M. \& K. Risager (i999) Language Teachers, Politics, and Cultures, Clevedon, Multilingual Matters.

Calvet, J. (20I8) Native-speakerism in the Catalan ELT professionalenvironment, Treball Final de Grau, Universitat de Lleida.

Cook, V. J. (1999) «Going beyond the native speaker in language teaching», TESOL Quarterly, 33 (2), p. I85-209. DOI: I0.2307/3587717

- (2005) «Basing teaching on the L2 user», dins E. Llurda (ed.), Non-Native Language

Teachers. Perceptions, Challenges and Contributions to the Profession, Nova York, Springer, p. 47-6I.

- (2007) «The Goals of ELT», dins J. Cummins \& C. Davison (ed.), International Handbook of English Language Teaching, Boston, Springer, p. 237-248.

Corcoll, C. \& M. González-Davies (2016) «Switching codes in the plurilingual classroom», ELT Journal, 70 (I), p. 67-77. DOI: 10.1093/elt/ccvo56

2. Agraeixo a un dels revisors anònims la idea de la importància del context i de l'interlocutor.

Caplletra 68 (Primavera, 2020), p. 199-217 
ENRIC LLURDA

Aprendre anglès per a parlar amb el món: reflexions al voltant de l'ensenyament de l'anglès com a llengua franca global

Crowther, D., P. Trofimovich, K. Saito \& T. Isaacs (20I5) «Second Language comprehensibility revisited: Investigating the effects of learner background", TESOL Quarterly, 49 (4), p. 8I4-838. DOI: I0.IO02/tesq.203.

Davies, A. (1991) The Native Speaker in Applied Linguistics, Edinburgh, Edinburgh University Press.

- (2003) The Native Speaker: Myth and reality, Clevedon, Multilingual Matters.

Derwing, T. M. \& M. J. Munro (20I5) Pronunciation Fundamentals: Evidence-Based Perspectives for L2 teaching, Amsterdam, John Benjamins.

GonzÁlez-Davies, M. (20I7) «The use of translation in an integrated plurilingual approach to language learning: teacher strategies and best practices», Journal of Spanish Language Teaching, 4 (2), p. I24-I35. DOI: 10.1080/23247797.2017.I407168

Jenkins, J. (2000) The Phonology of English as an International Language, Oxford, Oxford University Press.

Kachru, B. (1986) The Alchemy of English: The Spread, Functions and Models of NonNative Englishes, Oxford, Pergamon Press.

Kramsch, C. \&A. Whiteside (2007) «Three fundamental concepts in second language acquisition and their relevance in multilingual contexts", The Modern Language Journal, 9I (Focus Issue), p. 907-922. DOI: I0.IIII/j.I540-478I.2007.00677.x

LIu, J. (1999) «Nonnative English-speaking professionals in TESOL», TESOL Quarterly, 33 (I), p. 85-IO2. DOI: 10.2307/3588192

Llurda, E., ed. (2005) Non-Native Language Teachers. Perceptions, Challenges and Contributions to the Profession, New York, Springer.

- (2009) «Attitudes towards English as an international language: The pervasiveness of native models among L2 users and teachers», dins F. Sharifian (ed.) English as an International Language. Perspectives and Issues, Clevedon, Multilingual Matters, p. II9-I34.

- (2016) "Native speakers, English, and ELT: changing perspectives», dins G. Hall (ed.) The Routledge Handbook of English Language Teaching, Londres, Routledge, p. 5I-63.

- (20I8) «English language teachers and ELF», dins J. Jenkins, W. Baker \& M. Dewey (ed.) The Routledge Handbook of ELF, Londres, Routledge, p. 518-528.

Marlina, R. \& R. A. Giri, ed. (20I4) The Pedagogy of English as an International Language, Cham, Springer.

Matsuda, A., ed. (20I2) Principles and Practices of Teaching English as an International Language, Bristol, Multilingual Matters.

- ed. (2017) Preparing Teachers to Teach English as an International Language, Bristol, Multilingual Matters. 
ENRIC LLURDA

Aprendre anglès per a parlar amb el món: reflexions al voltant de l'ensenyament de l'anglès com a llengua franca global

MenARD-WARWICK, J. (2008) «The cultural and intercultural identities of transnational English teachers: Two case studies from the Americas», TESOL Quarterly, 42 (4), p. 6I7-640. DOI: I0.I002/j.I545-7249.2008.tboor5I.x.

Modiano, M. (I999) «International English in the global village», English Today, I5 (2), p. 22-28. DOI: I0.10I7/So26607840001083X

Moussu, L. \& E. Llurda (2008) «Non-native English-speaking English language teachers: History and research", Language Teaching, 4I (3), p. 315-348. DOI: IO.IOI7/So26I444808005028

O’Rourke, B. \& J. Pujolar (2013) «From native speakers to «new speakers» — problematizing nativeness in language revitalization contexts», Histoire Épistémologie Langage, 35 (2), p. 47-67.

Piller, I. (2002) «Passing for a native speaker: Identity and success in second language learning», Journal of Sociolinguistics, 6 (2), p. I79-206. DOI: I0.IIII/I467948I.0OI84

Rampton, M. B. H. (1990) «Displacing the 'native speaker': Expertise, affiliation, and inheritance», ELT Journal, 44 (2), p. 97-IOI. DOI: Io.I093/eltj/44.2.97

Risager, K. (2007) Language and culture pedagogy. From a national to a transnational paradigm, Clevedon, Multilingual Matters.

SeIdlHofer, B. (200I) «Closing a conceptual gap: The case for a description of English as a lingua franca», International Journal of Applied Linguistics, II (2), p. I33-I58. DOI: IO.IIII/I473-4192.000II

- (2003) A concept of International English and related issues: From 'real English' to 'realistic English', Strasbourg, Council of Europe.

Sercu, L, E. Bandura, P. Castro, L. Davcheva, C. Laskaridou, U. Lundgren, M. C. Méndez García \& P. Ryan (2005) Foreign Language Teachers and Intercultural Competence, Clevedon, Multilingual Matters.

Sifakis, N. C. \& N. Tsantila, ed. (20I9) English as a Lingua Franca for EFL Contexts, Bristol, Multilingual Matters.

VAN Essen (2002) «English is not English». Babylonia, I (2), p. IO-I5. [<http://babylonia. ch/fileadmin/user_upload/documents/2002-I/vanes.pdf $>$ ]

Widdowson, H. G. (1994) «The ownership of English», TESOL Quarterly, 28 (2), p. 377-389. DOI: $10.2307 / 3587438$

Caplletra 68 (Primavera, 2020), p. 199-217 